BMJ Open Diabetes

Research $\&$ Care

\title{
Type 2 diabetes in general practice in Norway 2005-2014: moderate improvements in risk factor control but still major gaps in complication screening
}

\author{
Åsne Bakke, ${ }^{1,2}$ John G Cooper, ${ }^{1,3}$ Geir Thue, ${ }^{2,3}$ Svein Skeie, ${ }^{4}$ Siri Carlsen, ${ }^{1,3}$ \\ Ingvild Dalen, ${ }^{5}$ Karianne Fjeld Løvaas, ${ }^{3}$ Tone Vonheim Madsen, ${ }^{3}$ \\ Ellen Renate Oord, ${ }^{1}$ Tore Julsrud Berg, ${ }^{6,7}$ Tor Claudi, ${ }^{8}$ Anh Thi Tran, ${ }^{9}$ \\ Bjørn Gjelsvik, ${ }^{9}$ Anne Karen Jenum, ${ }^{9}$ Sverre Sandberg ${ }^{2,3,10}$
}

\begin{abstract}
To cite: Bakke Å, Cooper JG, Thue G, et al. Type 2 diabetes in general practice in Norway 2005-2014: moderate improvements in risk factor control but still major gaps in complication screening. BMJ Open Diab Res Care 2017:5:e000459. doi:10.1136/ bmjdrc-2017-000459
\end{abstract}

- Additional material is published online only. To view please visit the journal online (http://dx.doi.org/10.1136/ bmjdrc-2017-000459).

Part of this work was presented as an oral presentation at the 52nd Annual Meeting of the Scandinavian Society for the Study of Diabetes, Nyborg, Denmark, 19-21 May 2017. It was presented as a poster at the 53rd European Association for the Study of Diabetes, Lisbon, Portugal, 11-15 September 2017.

Received 7 August 2017 Revised 29 September 2017 Accepted 20 0ctober 2017

\section{CrossMark}

For numbered affiliations see end of article.

Correspondence to Dr Åsne Bakke; asne.bakke@sus.no

\section{ABSTRACT}

Objective To assess the status of type 2 diabetes care in general practice and changes in the quality of care between 2005 and 2014, and to identify areas of diabetes care requiring improvement.

Research design and methods Two cross-sectional surveys were performed that included patients with type 2 diabetes in selected areas $(n=9464$ in $2014, n=5463$ in 2005). Quality of care was assessed based on key recommendations in national guidelines. Differences in clinical performance between 2005 and 2014 were assessed in regression models adjusting for age, sex, counties and clustering within general practices. Results Treatment targets were achieved in a higher proportion of patients in 2014 compared with 2005: hemoglobin $\mathrm{A} 1 \mathrm{c} \leq 7.0 \%$ ( $\leq 53 \mathrm{mmol} / \mathrm{mol})$ in $62.8 \%$ vs $54.3 \%$, blood pressure $\leq 135 / 80 \mathrm{~mm} \mathrm{Hg}$ in $44.9 \%$ vs $36.6 \%$, and total cholesterol $\leq 4.5 \mathrm{mmol} / \mathrm{L}$ in $49.9 \%$ vs $33.5 \%$ (all adjusted $\mathrm{P} \leq 0.001$ ). Regarding screening procedures for microvascular complications, fewer patients had recorded an eye examination $(61.0 \%$ vs $71.5 \%$, adjusted $\mathrm{P}<0.001$ ), whereas more patients underwent monofilament test $(25.9 \%$ vs $18.7 \%$, adjusted $\mathrm{P}<0.001)$. Testing for albuminuria remained low $(30.3 \%)$ in 2014 . A still high percentage were current smokers (22.7\%). Conclusions We found moderate improvements in risk factor control for patients with type 2 diabetes in general practice during the last decade, which are similar to improvements reported in other countries. We report major gaps in the performance of recommended screening procedures to detect microvascular complications. The proportion of daily smokers remains high. We suggest incentives to promote further improvements in diabetes care in Norway.

\section{INTRODUCTION}

Good glycemic control and appropriate management of cardiovascular risk factors in patients with type 2 diabetes reduce the risk of vascular complications and mortality. ${ }^{1-9}$ The

\section{Significance of this study}

What is already known about this subject?

- Adequate control of cardiovascular risk factors and the early detection of microvascular complications may prevent or delay the development of complications in type 2 diabetes.

What are the new findings?

- We found moderate improvements in blood pressure and lipid control between 2005 and 2014, but the performance of screening procedures for microvascular complications remained poor.

How might these results change the focus of research or clinical practice?

- The results should increase doctors' awareness of the importance of risk factor control and the early detection of microvascular complications, and may encourage the authorities to create systems that can help general practitioners to implement guideline recommendations.

Steno-2 trial found an increase in lifespan in high-risk patients with type 2 diabetes with a combined behavioral and pharmacological intervention in a specialist care setting. However, in most countries the majority of patients with type 2 diabetes are treated in primary care. The initial 5-year follow-up of the Anglo-Danish-Dutch Study of Intensive Treatment in People with Screen Detected Diabetes in Primary Care (ADDITION-Europe) trial of screening-detected patients with type 2 diabetes in general practice found improved risk factor levels and a trend toward a reduced rate of cardiovascular events, microvascular complications and death in the multifactorial treatment group compared 
with routine care. ${ }^{1011}$ A Swedish observational study with 13000 patients with type 2 diabetes from general practice in 2012 reported that fatal and non-fatal cardiovascular disease (CVD) decreased from $23.6 \%$ to $6.0 \%$ when they compared patients achieving a decrease versus an increase in hemoglobin A1c (HbAlc), blood pressure and lipids. ${ }^{4}$ It has also been shown that early detection of complications by systematic screening and intervention prevents or delays the development of target organ disease. ${ }^{12} 13$

Risk factor control and screening for early complications can only be closely monitored in countries with nationwide and comprehensive diabetes registries such as Sweden and Scotland. ${ }^{14}$ Other countries must perform cross-sectional surveys to assess status and time trends in diabetes care. ${ }^{16-19}$ In Norway, the quality of type 2 diabetes care has been assessed through repeated cross-sectional surveys (Rogaland-Oslo-Salten-Akershus-Hordaland (ROSA) studies) since 1995. The previous survey, ROSA 3, was performed in 2005 and showed substantial improvements in glycemic, blood pressure and lipid control between 1995 and 2005. ${ }^{2021}$

A new assessment of the quality of diabetes care was important for several reasons.

First, several new glucose-lowering agents have been approved since 2005 , and antihyperglycemic drug expenditure has increased by approximately $60 \%$ in Norway and the USA. ${ }^{22}{ }^{23}$ Second, during the last decade several large studies comparing different treatment targets for diabetes have failed to show additional benefit from extremely intensive treatment targets. ${ }^{24-26}$ As a result of these studies modern diabetes guidelines emphasize the importance of individual treatment targets that may influence the overall quality of care. ${ }^{27-29}$ Finally, Norway offers government-funded healthcare services to all inhabitants, and these services are expected to provide high-quality diabetes care. We therefore designed a large cross-sectional survey in 2014, the ROSA 4 study, with the objective of assessing the current status of type 2 diabetes care in general practice and changes in the quality of care between 2005 and 2014, and identifying areas of care requiring improvement.

\section{RESEARCH DESIGN AND METHODS}

ROSA 4 is a population-based cross-sectional survey designed to assess the quality of care of patients with type 2 diabetes in general practice in Norway in 2014. We included patients with diabetes living in urban and rural areas in 5 of 19 counties, covering more than $50 \%$ of the general population in Norway. General practitioners (GPs) in these areas were invited to participate, and 77 practices (73\% of the invited) with $282 \mathrm{GPs}$ ( $77 \%$ of the invited) agreed (figure 1). Data were collected from the electronic patient records from all the GPs within a practice by research nurses.

All adults ( $\geq 18$ years) with a diagnosis of diabetes (T89 and T90 in the International Classification of Primary

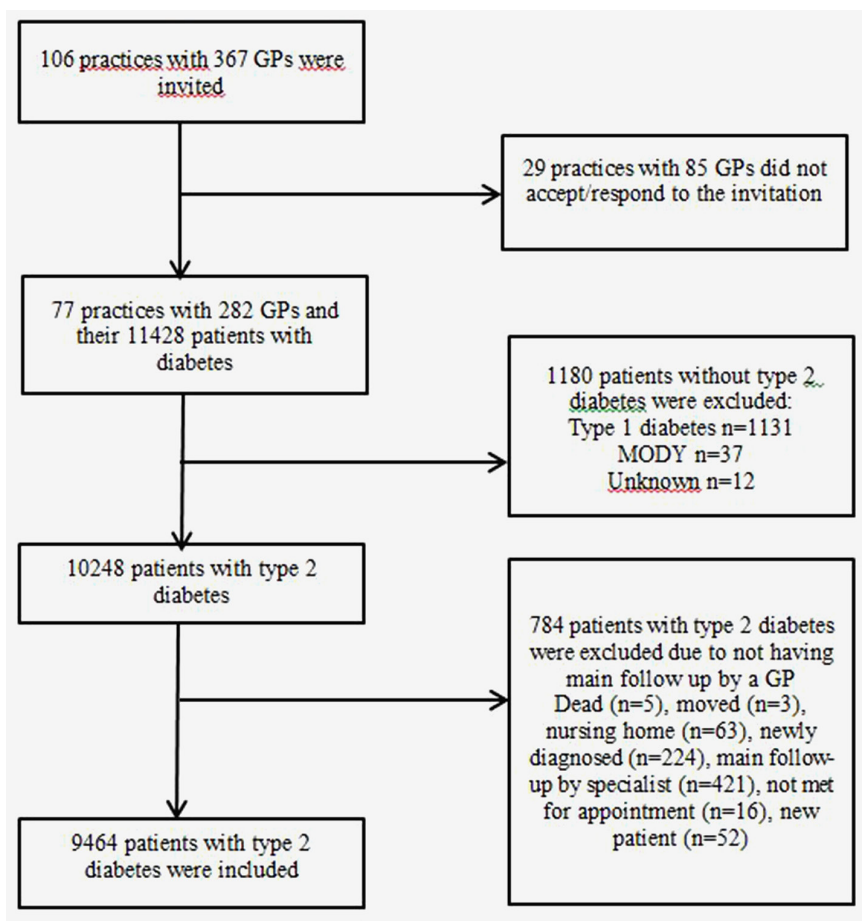

Figure 1 Flow chart of general practices and patients with diabetes included in the Rogaland-Oslo-Salten-AkershusHordaland study (ROSA 4) in 2014. GP, general practitioner; MODY, maturity onset diabetes of the young.

Care) between 2012 and 2014 were identified using customized software that also captured predefined data from the electronic patient records. The records were examined manually by research nurses to verify electronically registered data and to collect data not suitable for electronic capture. Data capture was performed in January 2015-April 2016.

The following variables were registered in the survey: patient characteristics (age, sex, ethnicity, diabetes duration, height and weight, smoking status); processes of care (documentation of HbAlc, blood pressure, lipids, creatinine/estimated glomerular filtration rate (eGFR), height and weight, smoking habits, eye examination, albuminuria, monofilament test); medication (antihyperglycemic, antihypertensive, antithrombotic and lipid-lowering therapy extracted from the GP's electronic prescription files); intermediate outcomes (HbA1c, blood pressure, cholesterol, low-density lipoprotein (LDL), creatinine/eGFR); and vascular complications (retinopathy, nephropathy (albuminuria, eGFR $<60 \mathrm{~mL} / \mathrm{min} / 1.73 \mathrm{~m}^{2}$ ), neuropathy (pathological $10 \mathrm{~g}$ monofilament test), foot ulcer, lower limb amputation, coronary heart disease (angina, myocardial infarction, percutaneous coronary intervention/coronary artery bypass surgery), stroke (excluding transient ischemic attacks (TIA)), atrial fibrillation, and percutaneous transluminal angioplasty/arterial surgery). In the present study we included the last registered value in 2014 for most variables, except for eye examination, creatinine/eGFR and lipids (last registered 2012-2014), 
and smoking habits (last registered 2010-2014) (online supplementary table $\mathrm{S} 1$ ). Medication was extracted from the GP's electronic prescriptions the last 15 months, October 1, 2013 to December 31, 2014.

Of the 11428 patients in the electronic patient records with diabetes, 10248 had type 2 diabetes. Patients who did not have their main follow-up in general practice (residential patients in nursing homes $(\mathrm{n}=63)$, patients attending a specialist clinic $>1$ time/year $(n=421)$, patients with a diabetes duration of less than 6 months and patients who had died or moved from the practice area during $2014(\mathrm{n}=300))$, in total $\mathrm{n}=784(8 \%)$, were excluded from the analysis, leaving 9464 patients with type 2 diabetes for statistical analysis (figure 1).

The ROSA 3 survey in 2005 used the same inclusion and exclusion criteria and methods of data extraction as ROSA $4,,^{20} 30$ and consisted of a sample of 5463 patients with type 2 diabetes treated in primary care, from 60 practices and 205 GPs (online supplementary figure 1). The ROSA 4 and ROSA 3 data sets used the same variable definition for almost all variables, except that the variable stroke excluded TIA in 2014, whereas TIA was included in 2005 (online supplementary table S1).

Quality of care was assessed against predefined review criteria based on key recommendations in the Norwegian 2009 guidelines ${ }^{31}$ : HbA1c $\leq 7.0 \%$ ( $53 \mathrm{mmol} / \mathrm{mol}$ ), intervention threshold blood pressure $>140 / 85 \mathrm{~mm} \mathrm{Hg}$ with treatment target $\leq 135 / 80 \mathrm{~mm} \mathrm{Hg}$, and total cholesterol $\leq 4.5 \mathrm{mmol} / \mathrm{L}$. LDL targets were introduced with revision of the guidelines in 2009 but were not used in the comparison analyses due to missing data in the ROSA 3 survey.

\section{Statistical analyses}

We compared 2014 data with 2005 in regression models while controlling for patient age, gender and county of GP practice. We present average adjusted predictions with CIs adjusted for clustering within GP practices. Differences were tested for statistical significance using Wald tests. We did not control for diabetes duration since new patients may have been diagnosed at an earlier stage in the ROSA 4 study due to the introduction of $\mathrm{HbAlc} \geq 6.5 \%(48 \mathrm{mmol} / \mathrm{mol})$ as diagnostic criterion. All statistical analyses were performed using STATA/ SE V.14.0 for Windows, with functions logit, mlogit and regress, and with margins and test postestimation procedures. In consideration of the large sample size and correspondingly high statistical power, we applied a somewhat strict criterion $(\mathrm{P} \leq 0.01)$ for statistical significance. In case of missing data, the percentages of valid cases and thus included cases are specified for each analysis.

In 2014, data were collected from two more counties than in 2005. We therefore performed a sensitivity analysis comparing data only from the three counties included in both ROSA 3 and 4. This analysis gave almost identical results for all variables (data not shown).

\section{RESULTS}

\section{Study samples}

In 2014, $73 \%$ of GP practices agreed to participate compared with $91 \%$ in 2005. We included 9464 (2014) and 5463 (2005) patients with type 2 diabetes. Characteristics of the study samples are presented in online supplementary table S2. There were more urban residents $(85.2 \%$ vs $80.4 \%)$ and more men (54.6\% vs $50.4 \%)$ included in 2014 compared with 2005, and the patients in 2014 also had a longer duration of diabetes (median duration 7 years vs 5 years). The samples were similar with regard to age, ethnicity, body mass index (BMI) and proportion of current smokers. The proportion of smokers was higher among patients $<60$ years vs $\geq 60$ years in both $2014(29.7 \%$ vs $19.3 \%)$ and 2005 (33.8\% vs $20.4 \%)$.

\section{Processes of care}

HbAlc, blood pressure and cholesterol were measured in most patients $(>85 \%)$ in both study years; however, HbAlc was performed in a lower proportion in 2014 compared with 2005 ( $86.4 \%$ vs $91.8 \%$, adjusted change -4.4 percentage points, $\mathrm{P}<0.001$ ) (table 1 ).

Frequencies of measurement of LDL and creatinine/ eGRF were also high in 2014, with $84.4 \%$ and $93.2 \%$ of patients, respectively. Recording of both height/weight to estimate BMI was low in both study years $(44.6 \%$ in 2014), whereas registration of smoking habits increased $(79.0 \%$ vs $56.0 \%$, adjusted change +24.9 percentage points, $\mathrm{P}<0.001)$. Procedures related to screening for microvascular complications differed between 2014 and 2005, with fewer patients undergoing eye examination in $2014(61.0 \%$ vs $71.5 \%$, adjusted change -7.1 percentage points, $\mathrm{P}<0.001)$ and more patients undergoing the monofilament test $(25.9 \%$ vs $18.7 \%$, adjusted change +12.3 percentage points, $\mathrm{P}<0.001)$. Testing for albuminuria remained low $(30.3 \%)$ in 2014.

\section{Medication}

Hyperglycemia was controlled by diet alone in approximately one-third of the patients in both surveys (table 2).

There was shift away from insulin in monotherapy toward other therapy schemes between 2005 and $2014(\mathrm{P}<0.001)$, and the overall frequency of the use of insulin also decreased $(14.7 \%$ vs $22.2 \%$, adjusted change -5.6 percentage points, $\mathrm{P}<0.001$ ). Significantly more patients were on combination therapy involving more than two agents in 2014 (9.5\% vs $1.8 \%$, adjusted change +6.9 percentage points). Metformin was the most frequently used antihyperglycemic agent in 2014 (57.9\%), and the use of metformin had increased substantially since 2005 (46.3\%; adjusted change +9.6 percentage points, $\mathrm{P}<0.001)$. Use of sulfonylureas, on the other hand, was reduced $(18.6 \%$ vs $30.7 \%$, adjusted change -12.4 percentage points, $\mathrm{P}<0.001)$. New glucose-lowering agents were used by one-fifth of the patients in 2014.

Sixty-six per cent of the patients received antihypertensive medication in both study years; however, 
Table 1 Processes of care documented in patients with type 2 diabetes in general practice in Norway in 2014 (ROSA 4) and 2005 (ROSA 3)

\begin{tabular}{|c|c|c|c|c|c|}
\hline \multirow[b]{2}{*}{ Processes of care } & \multicolumn{2}{|l|}{$\begin{array}{l}2014(n=9464) \\
\text { Percentages }\end{array}$} & \multicolumn{2}{|c|}{$\begin{array}{l}2005(n=5463) \\
\text { Percentages }\end{array}$} & \multirow{2}{*}{$\begin{array}{l}\text { Change from } 2005 \text { to } 2014 \\
\text { with } 95 \% \text { Cl } \\
\text { Percentage points }\end{array}$} \\
\hline & Observed, with $95 \% \mathrm{Cl} \dagger$ & Adjusted $\ddagger$ & Observed & Adjusted¥ & \\
\hline $\mathrm{HbA1c}$ & 86.4 (84.9 to 87.9$)$ & 86.8 & 91.8 & 91.3 & $-4.4(-6.7 \text { to }-2.1)^{\star \star}$ \\
\hline Blood pressure & 87.4 (85.8 to 89.0$)$ & 88.1 & 89.7 & 88.7 & -0.5 (-3.2 to 2.2$)$ \\
\hline Cholesterol & 89.0 (86.8 to 91.2$)$ & 89.0 & 89.5 & 89.6 & $-0.6(-3.7$ to 2.4$)$ \\
\hline LDL & 84.4 (81.1 to 87.7$)$ & 83.8 & 40.8 & 41.7 & +42.1 (32.9 to 51.2$)^{\star \star}$ \\
\hline Creatinine/eGFR & 93.2 (91.5 to 95.0$)$ & & NA & & \\
\hline Weight & 51.4 (46.7 to 56.1$)$ & 51.8 & 54.2 & 53.6 & $-1.8(-12.7$ to 9.1$)$ \\
\hline $\mathrm{BMI}$ & 44.6 (40.0 to 49.3$)$ & 45.1 & 36.9 & 36.3 & $+8.8(-1.9$ to 19.5$)$ \\
\hline Smoking habits & 79.0 (76.2 to 81.9$)$ & 79.6 & 56.0 & 54.6 & $+24.9(18.3 \text { to } 31.5)^{\star \star}$ \\
\hline Eye examination & $61.0(57.4$ to 64.6$)$ & 62.3 & 71.5 & 69.4 & $-7.1(-11.1 \text { to }-3.2)^{\star \star}$ \\
\hline Albuminuria & 30.3 (25.6 to 34.9$)$ & 31.3 & 37.9 & 36.1 & $-4.8(-13.8$ to 4.1$)$ \\
\hline Monofilament $10 \mathrm{~g}$ & 25.9 (21.5 to 30.3$)$ & 28.1 & 18.7 & 15.8 & $+12.3(6.6 \text { to } 17.9)^{\star \star}$ \\
\hline $\begin{array}{l}\text { Number of screening } \\
\text { procedures for microvascular } \\
\text { complications§ }\end{array}$ & & & & & ** \\
\hline 0 & 29.2 (25.7 to 32.8$)$ & 28.0 & 21.2 & 22.8 & $+5.2(0.5$ to 10.0$)$ \\
\hline 1 & 36.3 (34.2 to 41.6$)$ & 35.5 & 41.6 & 43.0 & $-7.5(-11.7$ to -3.4$)$ \\
\hline 2 & 22.5 (20.0 to 25.0 ) & 23.0 & 25.7 & 24.6 & $-1.6(-6.5$ to 3.2$)$ \\
\hline 3 & $12.0(9.1$ to 14.8$)$ & 13.4 & 11.6 & 9.6 & $+3.9(-0.8$ to 8.6$)$ \\
\hline
\end{tabular}

${ }^{*} \mathrm{P} \leq 0.01,{ }^{*} \mathrm{P} \leq 0.001$.

†Based on data as registered, 95\% Cls adjusted for clustering within GP practices.

$\ddagger$ Adjusted for sex, age, counties and clustering within GP practices.

$\S$ Screening procedures: eye examination, albuminuria and $10 \mathrm{~g}$ monofilament test.

BMI, body mass index; eGFR, estimated glomerular filtration rate; GP, general practitioner; HbA1c, hemoglobin A1c; LDL, low-density

lipoprotein; NA, notavailable; ROSA 3, Rogaland-Oslo-Salten study; ROSA 4, Rogaland-Oslo-Salten-Akershus-Hordaland study.

the use of ACE/AII inhibitors, calcium blockers and thiazides all increased (all $\mathrm{P} \leq 0.001$ ). The proportion of patients on lipid-lowering medication increased among patients with coronary heart disease $(77.9 \%$ vs $67.5 \%$, adjusted change +8.8 percentage points, $\mathrm{P}<0.001)$ as well as in general $(54.5 \%$ vs $43.7 \%$, adjusted change +11.3 percentage points, $\mathrm{P}<0.001)$.

\section{Measurements and attained treatment targets}

The patients achieved significantly more of the 2009 national treatment targets in 2014 than in $2005(\mathrm{P}<0.001)$, even though only $16.1 \%$ of the patients reached all three targets in 2014 (table 3).

$\mathrm{HbAlc} \leq 7.0 \% \quad(\leq 53 \mathrm{mmol} / \mathrm{mol})$ was achieved by $62.8 \%$ in 2014 vs $54.3 \%$ of the patients in 2005 (adjusted change +8.0 percentage points, $\mathrm{P}<0.001$ ), although the mean HbAlc levels declined by only 0.2 percentage points $(1.6 \mathrm{mmol} / \mathrm{mol})$ (adjusted; $\mathrm{P}<0.001)$. Among patients on diet only, a high proportion attained the HbAlc target in both study years (85.8\% in 2014), and in 2014 an improvement was seen among patients on medication $53.5 \%$ vs $43.7 \%$, adjusted change +7.9 percentage points, $\mathrm{P}=0.001)$. The proportion with $\mathrm{HbAlc}>9.0 \%$ $(>75 \mathrm{mmol} / \mathrm{mol})$ was fairly stable $(5.6 \%$ in 2014$)$.
More patients met blood pressure targets $(\leq 135 / 80 \mathrm{~mm} \mathrm{Hg}$ on antihypertensive medication and $\leq 140 / 85 \mathrm{~mm} \mathrm{Hg}$ without medication) in 2014 (50.3\% vs $42.3 \%$, adjusted change +7.2 percentage points, $\mathrm{P}=0.001$ ), and the mean adjusted systolic blood pressure decreased by $3.3 \mathrm{~mm} \mathrm{Hg}(\mathrm{P}<0.001)$.

Substantially more patients also achieved the total cholesterol target $(\leq 4.5 \mathrm{mmol} / \mathrm{L})$ in $2014 \quad(49.9 \%$ vs $33.5 \%$, adjusted change +15.4 percentage points, $\mathrm{P}<0.001)$. Among patients on lipid-lowering medication, the proportions reaching target total cholesterol were in general higher and also increasing (65.3\% vs $49.9 \%$, adjusted change +13.7 percentage points, $\mathrm{P}<0.001)$. The 2009 treatment target for LDL was met by $51.9 \%$ of all patients in 2014; however, among patients with coronary heart disease, the proportion with $\mathrm{LDL} \leq 1.8 \mathrm{mmol} / \mathrm{L}$ was substantially lower: $29.7 \%$.

\section{Vascular complications}

The proportion of patients with coronary heart disease was relatively stable $(22.0 \%$ in 2014) (table 4$)$.

There was a marked decrease in the proportion with neuropathy and with pathological monofilament test results among the relatively few patients registered 
Table 2 Overview of antihyperglycemic, antihypertensive, lipid-lowering and antithrombotic therapy in patients with type 2 diabetes in general practice in Norway in 2014 (ROSA 4) and 2005 (ROSA 3)

\begin{tabular}{|c|c|c|c|c|c|}
\hline \multirow[b]{2}{*}{ Medication } & \multicolumn{2}{|l|}{$\begin{array}{l}2014(\mathrm{n}=9464) \\
\text { Percentages }\end{array}$} & \multicolumn{2}{|c|}{$\begin{array}{l}2005(n=5463) \\
\text { Percentages }\end{array}$} & \multirow{2}{*}{$\begin{array}{l}\text { Change from } 2005 \text { to } \\
2014 \text { with } 95 \% \text { Cl } \\
\text { Percentage points }\end{array}$} \\
\hline & $\mathrm{Cl}+$ & Adjustedł & Observed & Adjusted $\ddagger$ & \\
\hline \multicolumn{6}{|l|}{ Antihyperglycemic therapy ${ }^{\star \star}$} \\
\hline Diet only & 31.7 (28.4 to 34.9$)$ & 32.5 & 28.2 & 27.0 & $+5.5(1.0$ to 10.1$)$ \\
\hline $\begin{array}{l}\text { Antihyperglycemic agents except for } \\
\text { insulin }\end{array}$ & 53.6 (50.8 to 56.5$)$ & 52.2 & 49.6 & 52.3 & $-0.1(-4.2$ to 4.1$)$ \\
\hline Insulin only & 5.4 (4.7 to 6.0$)$ & 5.6 & 12.4 & 11.6 & $-6.0(-7.9$ to -4.2$)$ \\
\hline $\begin{array}{l}\text { Insulin combined with other } \\
\text { antihyperglycemic agents }\end{array}$ & 9.3 (8.4 to 10.2$)$ & 9.7 & 9.7 & 9.1 & $+0.6(-0.7$ to 2.0$)$ \\
\hline \multicolumn{6}{|l|}{ Groups of antihyperglycemic agents } \\
\hline Metformin & 57.9 (54.7 to 61.1$)$ & 57.2 & 46.3 & 47.6 & $+9.6(5.2 \text { to } 14.1)^{\star \star}$ \\
\hline Sulfonylurea & 18.6 (17.0 to 20.3 ) & 18.5 & 30.7 & 31.0 & $\begin{array}{l}-12.4(-15.7 \text { to } \\
-9.1)^{\star \star}\end{array}$ \\
\hline Insulin & 14.7 (13.5 to 15.9$)$ & 15.3 & 22.2 & 20.9 & $-5.6(-8.2 \text { to }-3.1)^{\star \star}$ \\
\hline DPP-4 inhibitors & $13.9(12.0$ to 15.7$)$ & & NA & & \\
\hline GLP1 analogs & $2.6(2.1$ to 3.1$)$ & & NA & & \\
\hline SGLT2 inhibitors & $3.4(2.5$ to 4.4$)$ & & NA & & \\
\hline \multicolumn{6}{|c|}{ Numbers of antihyperglycemic agents, insulin included ${ }^{\star *}$} \\
\hline 1 & 36.2 (34.1 to 38.2$)$ & 36.0 & 43.8 & 44.4 & $-8.4(-11.7$ to -5.0$)$ \\
\hline 2 & 22.7 (21.3 to 24.0$)$ & 22.5 & 26.2 & 26.6 & $-4.2(-6.6$ to -1.7$)$ \\
\hline$\geq 3$ & 9.5 (8.5 to 10.5$)$ & 9.0 & 1.8 & 2.1 & $+6.9(5.9$ to 7.9$)$ \\
\hline \multicolumn{6}{|l|}{ Antihypertensive agents } \\
\hline Antihypertensives & $65.9(63.2$ to 68.6$)$ & 65.9 & 66.4 & 66.4 & $-0.5(-3.9$ to 2.9$)$ \\
\hline ACE/All inhibitors & 52.5 (50.1 to 54.8$)$ & 52.8 & 47.4 & 46.8 & $+6.0(2.3 \text { to } 9.6)^{\star \star}$ \\
\hline Beta blockers & 30.5 (28.6 to 32.3$)$ & 30.7 & 31.2 & 30.9 & $-0.3(-3.0$ to 2.5$)$ \\
\hline Calcium blockers & 25.9 (24.1 to 27.7$)$ & 26.6 & 22.2 & 21.2 & $+5.4(2.9 \text { to } 7.9)^{\star \star}$ \\
\hline Thiazides & 26.8 (25.1 to 28.6 ) & 27.4 & 22.0 & 21.2 & $+6.2(3.5 \text { to } 9.0)^{\star \star}$ \\
\hline \multicolumn{6}{|l|}{ Number of antihypertensives ${ }^{\star *}$} \\
\hline 1 & 19.2 (18.2 to 20.2) & 19.1 & 20.0 & 20.2 & $-1.1(-2.9$ to 0.8$)$ \\
\hline 2 & 20.3 (19.3 to 21.3 ) & 20.2 & 19.5 & 19.6 & $0.6(-1.2$ to 2.4$)$ \\
\hline 3 & 16.4 (15.3 to 17.4$)$ & 16.5 & 14.5 & 14.3 & $+2.2(0.6$ to 3.8$)$ \\
\hline$\geq 4$ & 10.0 (8.9 to 11.1$)$ & 10.4 & 12.4 & 11.6 & $-1.1(-3.1$ to 0.8$)$ \\
\hline Lipid-lowering medication & 54.5 (51.9 to 57.2$)$ & 54.7 & 43.7 & 43.4 & $+11.3(7.1 \text { to } 15.5)^{\star \star}$ \\
\hline With coronary heart disease & 77.9 (74.3 to 81.5$)$ & 77.3 & 67.5 & 68.5 & +8.8 (3.4 to 14.2$)^{\star \star}$ \\
\hline Antithrombotic therapy & 36.9 (34.7 to 39.2$)$ & 37.3 & 40.3 & 39.7 & $-2.5(-6.0$ to 1.1$)$ \\
\hline
\end{tabular}

Medication was extracted from the GP's electronic prescriptions. For antithrombotic therapy $0.6 \%$ ( $n=33$ ) were missing in 2005 , and for all other medication groups data were available in $100 \%$ of the cases.

${ }^{\star} \mathrm{P} \leq 0.01,{ }^{\star} \mathrm{P} \leq 0.001$.

†Based on data as registered, 95\% Cls adjusted for clustering within GP practices.

$\ddagger$ Adjusted for sex, age, counties and clustering within GP practices.

DPP-4, Dipeptidyl peptidase-4; GLP1, Glucagon-like peptide-1; NA, notavailable; ROSA 3, Rogaland-Oslo-Salten study; ROSA 4, Rogaland-

Oslo-Salten-Akershus-Hordaland study; SGLT2, Sodium-glucose co-transporter-2.

with these variables. Chronic kidney disease as evaluated by eGFR $<60 \mathrm{~mL} / \mathrm{min}$ was present in $17.3 \%$ of the patients in 2014, whereas $1.7 \%$ had eGFR of less than $30 \mathrm{~mL} / \mathrm{min}$.

\section{DISCUSSION}

We found clinically important improvements in the percentages attaining recommended targets for HbAlc, blood pressure and lipids in 2014 vs 2005 . However, the 


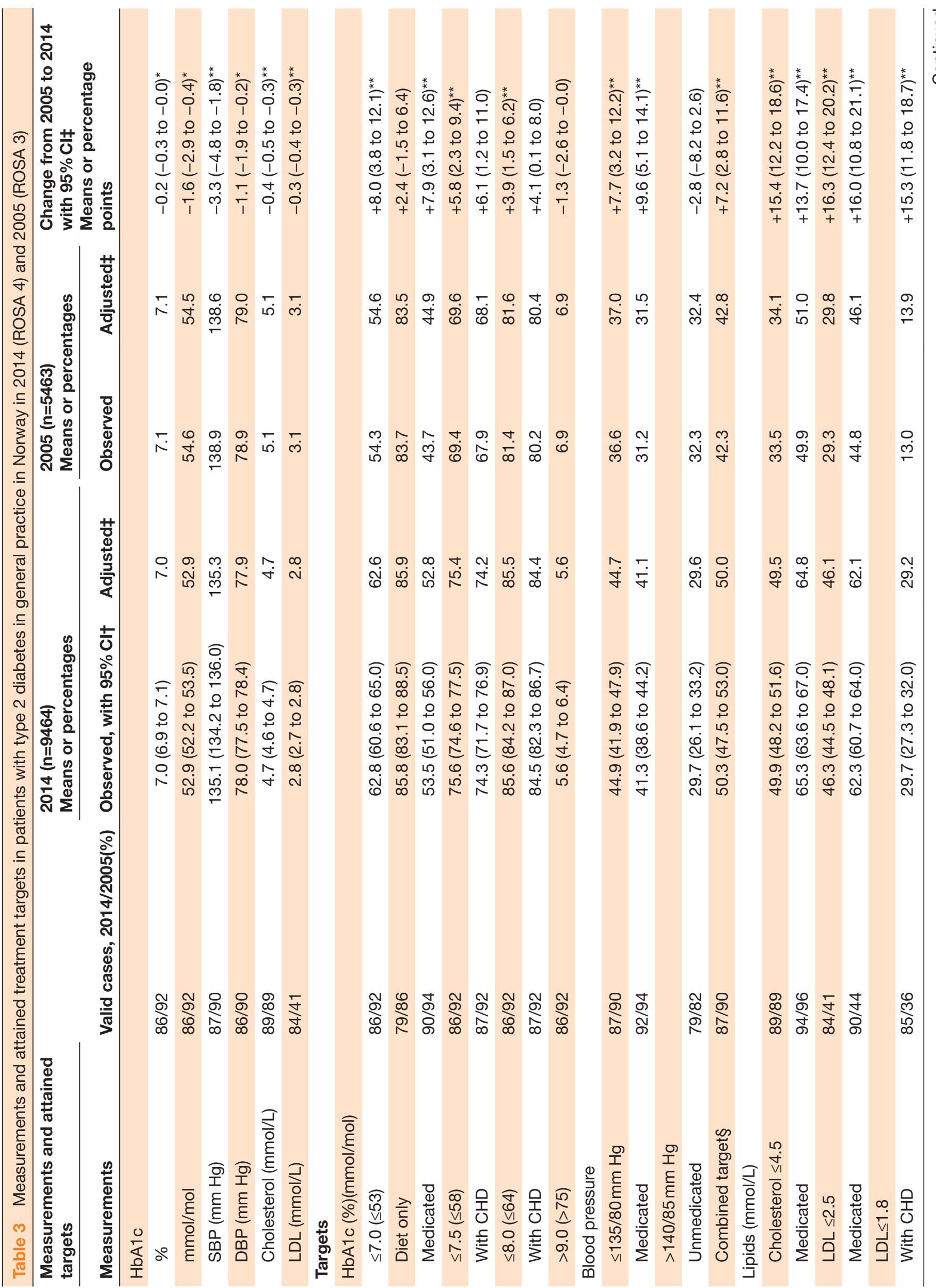


recording of screening procedures for microvascular complications remained alarmingly poor. Furthermore, the proportion of current smokers was disturbingly high.

\section{Study samples}

We consider our findings to be representative for patients with type 2 diabetes treated by GPs in Norway. In both the ROSA 4 and ROSA 3 surveys, data were collected from routine clinical practice, with all GPs in a practice participating. Furthermore, patients in the 2014 survey were similar to the type 2 diabetes population in the comprehensive Swedish and Scottish diabetes registries in 2014 and with other recently published surveys from Europe and the USA with respect to age, gender, diabetes duration and BMI. ${ }^{9} 141518$ 32-35

\section{Processes of care}

Recordings of HbA1c, blood pressure, lipids and smoking status in 2014 were acceptable and comparable to other surveys, while recording of weight/BMI was low. ${ }^{141536}$ Screening for microvascular complications was poor and inferior to that found in the diabetes registries from Sweden and Scotland, in the UK National Diabetes Audit and in cross-sectional studies in the USA. ${ }^{14-16} 36$ When comparing the results from ROSA 4 with Sweden, Scotland, UK and the USA, the proportions with annual checks for albuminuria were $30 \%$ vs $73 \%-75 \%$, neuropathy $26 \%$ vs $71 \%-94 \%$, and eye examination $61 \%$ vs $70 \%-90 \%$. Surprisingly, the percentage of patients with a recorded ophthalmological examination was lower in 2014 than in 2005. The differences between Norway and Sweden may be due to the use of reminders on the fill-in forms used by practices to report to the registry and the availability of diabetes specialist nurses in GP practices in Sweden. In addition, national initiatives in the UK to improve care for people with diabetes may have led to increasing screening rates, that is, the National Service Framework for Diabetes. ${ }^{37}$ In pediatric diabetes care in Norway, it has been shown that establishment of a nationwide system for benchmarking of quality indicators resulted in significant improvements in risk factor control and screening assessments. ${ }^{38}$

In the general population in Norway, the percentage of current smokers decreased from 24\% in 2004 to $13 \%$ in $2014 .{ }^{39}$ In contrast the prevalence of current smokers in ROSA 4 remained high $(22.0 \%)$ and similar to reports from the American National Health and Nutrition Examination Survey (NHANES), where the prevalence remained unchanged at $22 \%$ between 1999-2002 and 2007-2010. ${ }^{16}$ Corresponding percentages in Sweden and Scotland in 2014 were 15\% and $18 \% .{ }^{14}{ }^{15}$ A Swedish study found an excess mortality in patients with type 2 diabetes younger than 55 years, and $38 \%$ of these were current smokers. ${ }^{9}$ Motivating patients with diabetes to stop smoking should be an important priority for GPs. 


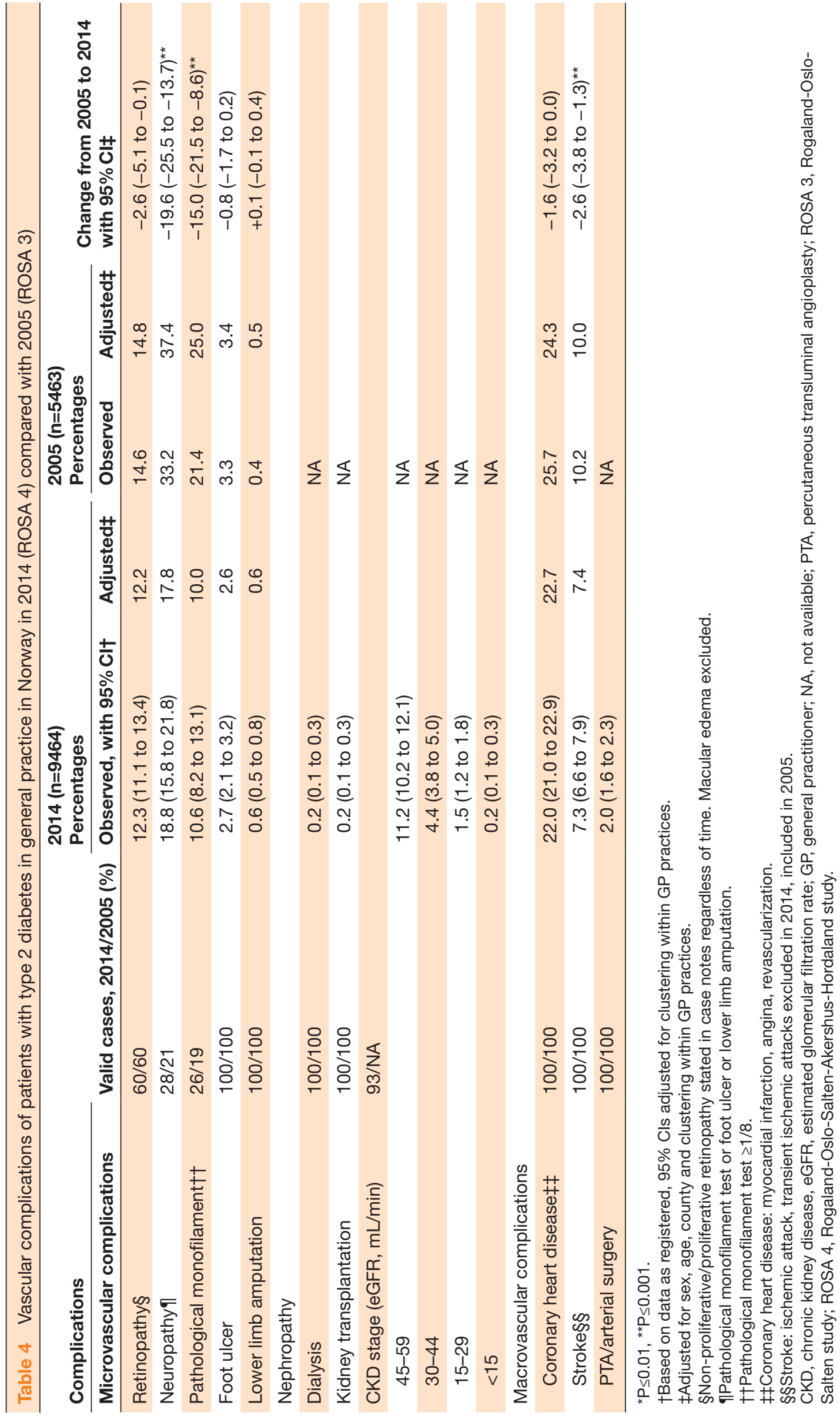


Medication, measurements and attained treatment targets

In accordance with national guidelines, the percentage of patients using metformin increased. The use of sulfonylureas decreased substantially (-12 percentage points). The same trends were seen in a recent publication from the USA. ${ }^{35}$

Risk factor control has improved during the last decade. The increase in achievement of HbA1c targets was similar to the observations between the periods 1999-2002 and 2007-2010 in NHANES (+8 percentage points). ${ }^{16}$ Compared with recent cross-sectional studies or annual reports from diabetes registries of type 2 diabetes in general practice worldwide, the proportion of patients achieving HbAlc $<7.0 \%(<53 \mathrm{mmol} / \mathrm{mol})$ in ROSA 4 was $57 \%$ vs $47 \%-52 \% .^{15161819}$ This confirms that glycemic control in Norwegian general practice is similar to other countries. We only found a slight improvement in mean HbA1c that was similar to findings in reports from the Swedish Diabetes Registry and NHANES. ${ }^{14} 16$ The decrease in mean $\mathrm{HbAlc}$ was only 0.2 percentage points $(1.6 \mathrm{mmol} / \mathrm{mol})$ despite the fact that antihyperglycemic drug expenditures increased by $60 \%$. The relatively small decline in mean $\mathrm{HbAlc}$ seen during the last decade may be due to the reduction of the use of insulin. It is possible that the GPs postpone insulin treatment, and start with the new expensive antihyperglycemic agents, which have less glucose-lowering effect than insulin. During recent years guidelines have emphasized the need for individual glycemic treatment targets for patients with long diabetes duration and comorbidities. ${ }^{27-29}$ These targets are often less intensive than previously strict recommendations and may also explain the clinically insignificant change in mean HbA1c. Finally, mean HbA1c is now at such a low level that lower mean values are difficult to achieve in large study populations.

There was no significant decrease in BMI in 2014 compared with 2005 despite the introduction of weight-neutral and weight-reducing therapies. However, the proportion of patients on such therapies was relatively low in 2014 (Dipeptidyl peptidase 4 (DPP4) inhibitors $13.9 \%$, Sodium-glucose co-transporter-2 (SGLT2) inhibitors, 3.4\%, Glucagon-like peptide-1 (GLP1) analogs $2.6 \%)$.

The increased use of ACE/II inhibitors, calcium blockers and thiazides probably explains the improved blood pressure control. However, there is still a high proportion of untreated patients above intervention threshold and treated patients above blood pressure targets. In our present study $38.5 \%$ achieved a blood pressure $\leq 130 / 80 \mathrm{~mm} \mathrm{Hg}$ (regardless of medication) in 2014. Findings from other countries span from $33.8 \%$ (Scotland) and $41.6 \%$ (Swedish Diabetes Registry), to $51.3 \%$ (NHANES). ${ }^{151619}$

The improved control of dyslipidemia might be influenced by the introduction of LDL targets in national guidelines in 2009. ${ }^{31}$ The proportion of patients on lipid-lowering therapy with cholesterol $<4.5 \mathrm{mmol} / \mathrm{L}$ was similar in ROSA 4 and the Swedish Diabetes Registry
$(62.0 \%$ vs $59.0 \%)$, while the Swedish had a higher proportion with $\mathrm{LDL}<2.5 \mathrm{mmol} / \mathrm{L}(42.3 \%$ vs $52.6 \%)$. The use of statins in ROSA 4 was inferior to Sweden $(54.5 \%$ vs $63.7 \%$ ). Only $28.5 \%$ of patients with a history of CVD attained LDL target $\leq 1.8 \mathrm{mmol} / \mathrm{L}$, similar to results from NHANES $(27.5 \%){ }^{16}$ This indicates that more patients with diabetes should start lipid-lowering therapy in Norway and that GPs should maintain efforts to achieve the strict LDL target in high-risk persons with CVD.

\section{Vascular complications}

There was no significant change in the prevalence of coronary heart disease during the last decade in our study populations. This is similar to the findings in two recent cross-sectional surveys from the USA. ${ }^{33} 35$ The prevalence of microvascular complications in our study is subject to uncertainty due to poor recording of screening among GPs in both surveys ( $60 \%$ eye examination, $\sim 30 \%$ albuminuria test and $\sim 25 \%$ monofilament test in 2014). We found no significant change in retinopathy between ROSA 4 and ROSA 3, but the $12.3 \%$ prevalence of patients with retinopathy in 2014 is probably underestimated due to inconsistent reporting. The Swedish Adult Diabetes Register reports a prevalence of retinopathy of $29.6 \%$ in their annual 2014 report. Their findings are probably more representative of retinopathy among patients with type 2 diabetes in general practice in Scandinavia. ${ }^{14}$ Fewer persons had neuropathy in ROSA 4 compared with ROSA 3, while more patients had a recorded monofilament test. The finding may be explained by selection bias if GPs in 2005 used monofilament test more frequently in patients suspected of having neuropathy. The prevalence of neuropathy in 2014 (18.8\%) is in agreement with reports from the Swedish National Diabetes Register 2014 (21\%), and both countries have $\sim 2.7 \%$ with a history of foot ulcer. ROSA 4 and Scotland report similar percentages of lower limb amputation $(0.6 \%$ and $0.7 \%$, respectively). ROSA 4 and Scotland have the same proportion of patients with end-stage renal failure $(0.6 \%)$.

\section{Strengths and weaknesses}

This study is one of the largest representative cross-sectional studies of type 2 diabetes in general practice performed in recent years, originating from a high-income country with an apparently well-organized healthcare system. Our study has some limitations. Screening procedures for microvascular complications are based on recorded data in the case notes. If GPs fail to record performed procedures, our results will overestimate the quality gaps. The level of albuminuria is not reported due to different measurement methods/units between GP practices, and frequent missing data. Finally, we excluded patients with main-follow up in specialist healthcare who probably had worse glycemic control; however, the absolute numbers were small and unlikely to influence the results $(4.4 \%$ in 2014 vs $5.0 \%$ in 2005 ). 
In summary, we found moderate improvements in blood pressure and lipid control during the last decade, which are similar to improvements reported from other countries. Improvements during the last decade are less striking than improvements reported in the previous decade. We demonstrated that there are still major gaps in the performance of recommended screening procedures to detect microvascular complications. Clinical performance in this area was considerably worse than other comparable countries. We also found a disturbingly high proportion of current smokers diverging from trends seen in the general Norwegian population. There is still considerable room for improvements of many aspects of diabetes care in general practice. Screening for microvascular complications must be improved. Risk factor control, especially the treatment of dyslipidemia, and the promotion of smoking cessation require attention. We suggest compulsory reporting to a national diabetes register and feedback to GPs as a means of continually evaluating diabetes control and promoting further improvements in diabetes care in Norway. A national screening program for diabetes retinopathy should also be considered.

\section{Author affiliations}

${ }^{1}$ Department of Endocrinology, Stavanger University Hospital, Stavanger, Norway ${ }^{2}$ Department of Global Public Health and Primary Care, University of Bergen, Bergen, Norway

${ }^{3}$ Norwegian Quality Improvement of Laboratory Examinations, Haraldsplass Deaconess Hospital, Bergen, Norway

${ }^{4}$ Department of Research, Stavanger University Hospital, Stavanger, Norway ${ }^{5}$ Department of Research, Section of Biostatistics, Stavanger University Hospital, Stavanger, Norway

${ }^{6}$ Institute of Clinical Medicine, Faculty of Medicine, University of Oslo, Oslo, Norway ${ }^{7}$ Department of Endocrinology, Morbid Obesity and Preventive Medicine, Oslo University Hospital, Oslo, Norway

${ }^{8}$ Department of Medicine, Nordland Hospital, Bodø, Norway

${ }^{9}$ Department of General Practice, Institute of Health and Society, University of Oslo, Oslo, Norway

${ }^{10}$ Laboratory of Clinical Biochemistry, Haukeland University Hospital, Bergen, Norway

Acknowledgements The authors thank the GPs and the GP practices for participating in the study. The authors also thank the research nurses who collected the data and Kaare Johansson, a representative of the user, who contributed to discussions prior to writing the manuscript.

Contributors ÅB quality-checked, analyzed the data and performed the statistical analyses, and drafted, reviewed and edited the manuscript. JGC, AKJ conceived the study protocol and analysis plan, applied to the Regional Ethics Committee, invited GPs and GP practices, contributed to the discussion, and reviewed and edited the manuscript. SSa, GT, TC, ATT, BG, TJB, KFL, TVM conceived the study protocol and analysis plan, invited GPs and GP practices, contributed to the discussion, and reviewed and edited the manuscript. ID supervised the statistical analyses, contributed to the discussion, and reviewed and edited the manuscript. ERO conceived the study protocol, collected the data, contributed to the discussion and reviewed the manuscript. SSk, SC contributed to the discussion, and reviewed and edited the manuscript. ÅB is the guarantor of this work, and as such had full access to all the data in the study and takes responsibility for the integrity of the data and the accuracy of the data analyses.

Funding ExtraStiftelsen and the Endocrinology Research Foundation, Stavanger, supports the doctoral program of ÅB and made this publication possible. ExtraStiftelsen supports ATT. The data collection of the ROSA 4 study was supported financially with grants from the Norwegian Diabetes Association, a consortium of 6 pharmaceutical firms (AstraZeneca, Boehringer Ingelheim, Eli Lilly,
MSD, Novo Nordisk and Sanofi Aventis), Helse Nord, the Endocrinology Research Foundation, Stavanger, and the University of Oslo. The funders had no involvement in the study design, analysis and interpretation of the data, or in the writing of the report and revision of the paper. The contents of this publication are solely the responsibility of the authors.

Competing interests The data collection was funded (see Funding for details). ÅB has received lecturing fees from Eli Lilly, Boehringer Ingelheim and Sanofi Aventis. JGC has received lecturing fees and financial support to attend EASD, IDF and ADA meetings from AstraZeneca, Boehringer Ingelheim, Eli Lilly, MSD, Novo Nordisk and Sanofi Aventis. The other authors have no disclosures.

Ethics approval Regional Ethical Committee in Norway (2014/1374 REK Vest). Provenance and peer review Not commissioned; externally peer reviewed. Data sharing statement The ROSA 4 database is securely stored for at least 20 years and will be available for future research to members of the ROSA 4 Research Collaboration.

Open Access This is an Open Access article distributed in accordance with the Creative Commons Attribution Non Commercial (CC BY-NC 4.0) license, which permits others to distribute, remix, adapt, build upon this work non-commercially, and license their derivative works on different terms, provided the original work is properly cited and the use is non-commercial. See: http://creativecommons.org/ licenses/by-nc/4.0/

(c) Article author(s) (or their employer(s) unless otherwise stated in the text of the article) 2017. All rights reserved. No commercial use is permitted unless otherwise expressly granted.

\section{REFERENCES}

1. Kearney PM, Blackwell L, Collins R, et al. Efficacy of cholesterollowering therapy in 18,686 people with diabetes in 14 randomised trials of statins: a meta-analysis. Lancet 2008;371:117-25.

2. Holman RR, Sourij H, Califf RM. Cardiovascular outcome trials of glucose-lowering drugs or strategies in type 2 diabetes. Lancet 2014:383:2008-17.

3. Bajaj H, Zinman B. Diabetes: Steno-2 - a small study with a big heart. Nat Rev Endocrinol 2016;12:692-4.

4. Eeg-Olofsson K, Zethelius B, Gudbjörnsdottir S, et al. Considerably decreased risk of cardiovascular disease with combined reductions in $\mathrm{HbA1c}$, blood pressure and blood lipids in type 2 diabetes: Report from the Swedish National Diabetes Register. Diab Vasc Dis Res 2016;13:268-77.

5. Gæde P, Oellgaard J, Carstensen B, et al. Years of life gained by multifactorial intervention in patients with type 2 diabetes mellitus and microalbuminuria: 21 years follow-up on the Steno-2 randomised trial. Diabetologia 2016;59:2298-307.

6. Intensive blood-glucose control with sulphonylureas or insulin compared with conventional treatment and risk of complications in patients with type 2 diabetes (UKPDS 33). UK Prospective Diabetes Study (UKPDS) Group. Lancet 1998;352:837-53.

7. Effect of intensive blood-glucose control with metformin on complications in overweight patients with type 2 diabetes (UKPDS 34). UK Prospective Diabetes Study (UKPDS) Group. Lancet 1998;352:854-65.

8. Tight blood pressure control and risk of macrovascular and microvascular complications in type 2 diabetes: UKPDS 38. UK Prospective Diabetes Study Group. BMJ 1998;317:703-13.

9. Tancredi M, Rosengren A, Svensson AM, et al. Excess mortality among persons with type 2 diabetes. $N$ Engl J Med 2015;373:1720-32

10. Griffin SJ, Borch-Johnsen K, Davies MJ, et al. Effect of early intensive multifactorial therapy on 5-year cardiovascular outcomes in individuals with type 2 diabetes detected by screening (ADDITIONEurope): a cluster-randomised trial. Lancet 2011;378:156-67.

11. Simmons RK, Borch-Johnsen K, Lauritzen T, et al. A randomised trial of the effect and cost-effectiveness of early intensive multifactorial therapy on 5-year cardiovascular outcomes in individuals with screen-detected type 2 diabetes: the Anglo-Danish-Dutch Study of Intensive Treatment in People with Screen-Detected Diabetes in Primary Care (ADDITION-Europe) study. Health Technol Assess 2016;20:1-86.

12. Gaede P, Vedel P, Larsen N, et al. Multifactorial intervention and cardiovascular disease in patients with type 2 diabetes. $N$ Engl $J$ Med 2003;348:383-93.

13. Zoungas $\mathrm{S}$, Arima H, Gerstein $\mathrm{HC}$, et al. Effects of intensive glucose control on microvascular outcomes in patients with type 2 diabetes: 
a meta-analysis of individual participant data from randomised controlled trials. Lancet Diabetes Endocrinol 2017;5:431-7.

14. Nationella Diabetes registret. Nationella diabetes registret 2014. https://www.ndr.nu/pdfs/Arsrapport_NDR_2014.pdf(accessed 1 Aug 2017).

15. Scottish Diabetes Survey. Scottish diabetes survey 2014, 2014. http://www.diabetesinscotland.org.uk/Publications/SDS2014. pdf(accessed 1 Aug 2017).

16. Ali MK, Bullard KM, Saaddine JB, et al. Achievement of goals in U.S. diabetes care, 1999-2010. N Engl J Med 2013;368:1613-24.

17. Kloos C, Müller N, Hartmann P, et al. High quality of diabetes care based upon individualised treatment goals - a cross sectional study in 4784 patients in Germany. Exp Clin Endocrinol Diabetes 2016;124:294-9.

18. Miñambres I, Mediavilla JJ, Sarroca J, et al. Meeting individualized glycemic targets in primary care patients with type 2 diabetes in Spain. BMC Endocr Disord 2016;16:10.

19. Yokoyama $\mathrm{H}$, Oishi M, Takamura $\mathrm{H}$, et al. Large-scale survey of rates of achieving targets for blood glucose, blood pressure, and lipids and prevalence of complications in type 2 diabetes (JDDM 40). BMJ Open Diabetes Res Care 2016;4:e000294.

20. Claudi T, Ingskog W, Cooper JG, et al. [Quality of diabetes care in Norwegian general practice]. Tidsskr Nor Laegeforen 2008;128:2570-4

21. Jenum AK, Claudi T, Cooper JG. Primary care diabetes in Norway. Prim Care Diabetes 2008;2:203-5.

22. Folkehelseinstituttet. Reseptregisteret. http://www.reseptregisteret. no/(accessed 1 Aug 2017).

23. Turner LW, Nartey D, Stafford RS, et al. Ambulatory treatment of type 2 diabetes in the U.S., 1997-2012. Diabetes Care 2014;37:985-92.

24. Gerstein HC, Miller ME, Byington RP, et al. Effects of intensive glucose lowering in type 2 diabetes. $N$ Engl $\mathrm{J}$ Med 2008;358:2545-59.

25. Patel A, MacMahon S, Chalmers J, et al. Intensive blood glucose control and vascular outcomes in patients with type 2 diabetes. $N$ Engl J Med 2008;358:2560-72.

26. Duckworth W, Abraira C, Moritz T, et al. Glucose control and vascular complications in veterans with type 2 diabetes. N Engl $J$ Med 2009;360:129-39.

27. Helsedirektoratet. Nasjonal fagligretningslinje for diabetes, 2016. https://helsedirektoratet.no/retningslinjer/diabetes(accessed 1 Aug 2017).
28. NICE. NICE guidelines NG28, 2016. https://www.nice.org.uk/ guidance/ng28/chapter/1-Recommendations(accessed 1 Aug 2017).

29. American Diabetes Association. 9. Cardiovascular disease and risk management. Diabetes Care 2017;40:S75-S87.

30. Cooper JG, Claudi T, Jenum AK, et al. Quality of care for patients with type 2 diabetes in primary care in Norway is improving: results of cross-sectional surveys of 33 general practices in 1995 and 2005. Diabetes Care 2009;32:81-3.

31. Helsedirektoratet. Nasjonale faglige retningslinjer med anbefalinger om forebygging,diagnostikk og behandling av diabetes, 2009. https://helsedirektoratet.no/retningslinjer/diabetes-nasjonal-fagligretningslinje(accessed 1 Aug 2017).

32. Pérez A, Mediavilla JJ, Miñambres I, et al. Glycemic control in patients with type 2 diabetes mellitus in Spain. Rev Clin Esp 2014;214:429-36.

33. Pantalone KM, Hobbs TM, Wells BJ, et al. Clinical characteristics, complications, comorbidities and treatment patterns among patients with type 2 diabetes mellitus in a large integrated health system. BMJ Open Diabetes Res Care 2015;3:e000093.

34. Ali MK, Singh K, Kondal D, et al. Effectiveness of a multicomponent quality improvement strategy to improve achievement of diabetes care goals: A randomized, controlled trial. Ann Intern Med 2016;165:399-408.

35. Lipska KJ, Yao X, Herrin J, et al. Trends in drug utilization, glycemic control, and rates of severe hypoglycemia, 2006-2013. Diabetes Care 2017;40:468-75.

36. Healthcare Quality Improvement Partnership. National diabetes audit, 2015. http://www.hqip.org.uk/resources/national-diabetesaudit-2013-2014-2014-2015-report-1-care-processes-andtreatment-targets/(accessed 1 Aug 2017).

37. UK Department of Health. Six years on: Delivering the diabetes national service framework, 2010. http://webarchive.nationalarchives gov.uk/20130107105354/http:/www.dh.gov.uk/en/Publicationsand statistics/Publications/PublicationsPolicyAndGuidance/DH_112509 (accessed 1 Aug 2017).

38. Margeirsdottir HD, Larsen JR, Kummernes SJ, et al. The establishment of a new national network leads to quality improvement in childhood diabetes: implementation of the ISPAD Guidelines. Pediatr Diabetes 2010;11:88-95.

39. Folkehelseinstituttet. Røyking, 2014. https://www.fhi.no/ml/royking/ royk-og-snus-faktaark-med-statist/(accessed 1 Aug 2017). 